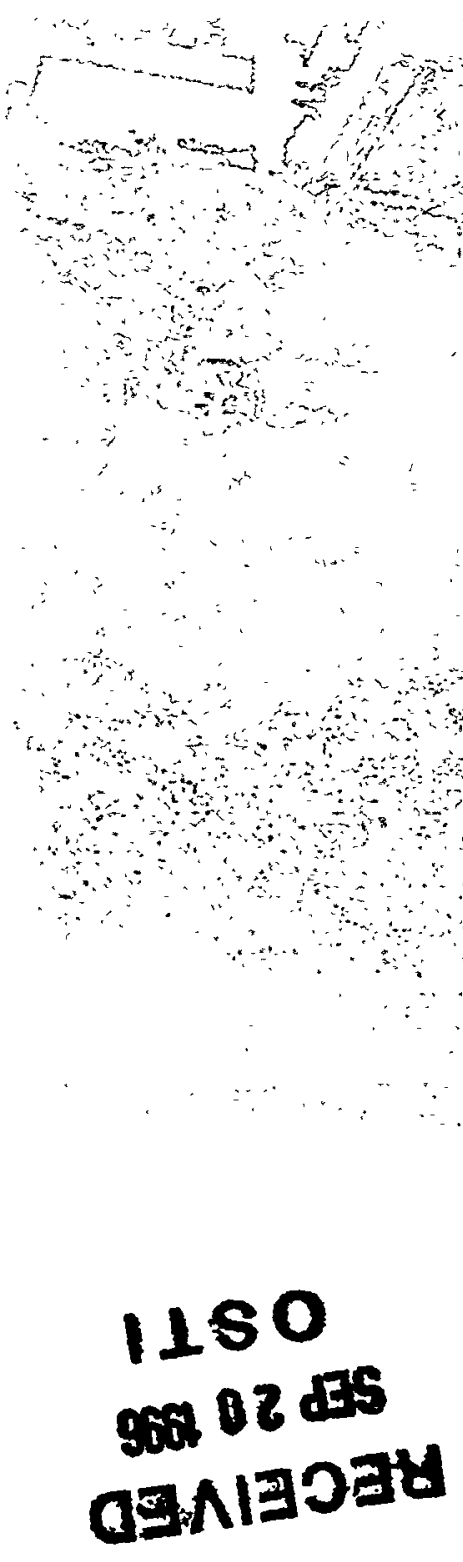

966L KEW

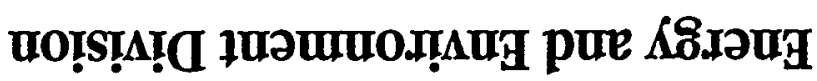
วџग!d $\mathrm{VW}$

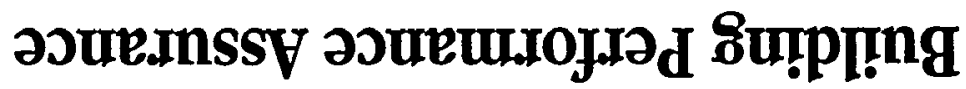

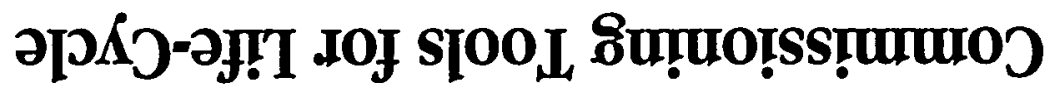

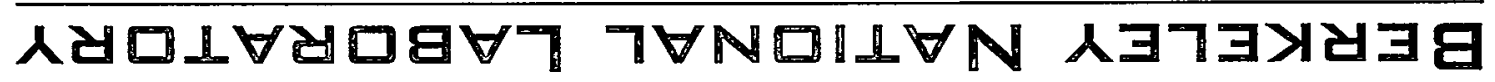

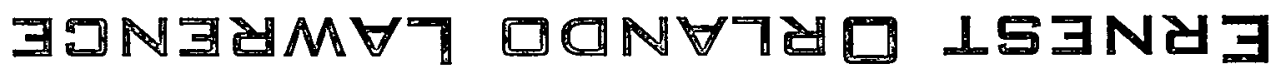




\section{DISCLAIMER}

This document was prepared as an account of work sponsored by the United States Government. While this document is believed to contain correct information, neither the United States Government nor any agency thereof, nor The Regents of the University of California, nor any of their employees, makes any warranty, express or implied, or assumes any legal responsibility for the accuracy, completeness, or usefulness of any information, apparatus, product, or process disclosed, or represents that its use would not infringe privately owned rights. Reference herein to any specific commercial product, process, or service by its trade name, trademark, manufacturer, or otherwise, does not necessarily constitute or imply its endorsement, recommendation, or favoring by the United States Government or any agency thereof, or The Regents of the University of California. The views and opinions of authors expressed herein do not necessarily state or reflect those of the United States Government or any agency thereof, or The Regents of the University of California.

Ernest Orlando Lawrence Berkeley National Laboratory is an equal opportunity employer.

$$
+
$$


LBNL-38979

UC-1600

\title{
Commissioning Tools for Life-Cycle Building Performance Assurance
}

\author{
Mary Ann Piette \\ Energy \& Environment Division \\ Lawrence Berkeley National Laboratory \\ University of California \\ Berkeley, CA 94720
}

May 1996

This work was partially supported by the Director, Office of Energy Efficiency and Renewable Energy, Building Systems Division of the U.S. Department of Energy under Contract No. DE-AC03-76SF00098. 
La 


\section{DISCLAIMER}

Portions of this document may be illegible in electronic image products. Images are produced from the best available original document. 


\title{
Commissioning Tools for Life-Cycle Building Performance Assurance
}

\author{
Mary Ann Piette \\ Lawrence Berkeley National Laboratory
}

\section{Synopsis}

This paper discusses information systems for building life-cycle performance analysis and the use of computer-based commissioning tools within this context. There are many reasons why buildings do not perform in practice as well as intended at the design stage. One reason is the lack of commissioning. A second reason is that design intent is not well documented, and performance targets for building components and systems are not well specified. Thus, criteria for defining verification and functional tests is unclear. A third reason is that critical information is often lost throughout the building life-cycle, which causes problems such as misunderstanding of operational characteristics and sequences and reduced overall performance. The life-cycle building performance analysis tools project discussed in this paper are focused on chillers and cooling systems.

\section{About the Author}

Mary Ann Piette is a Staff Scientist at the Lawrence Berkeley National Laboratory, where she has worked since 1983. Her work emphasizes data collection and analysis of the energy performance of commercial buildings. Project experiences range from whole-building energy analysis of new and retrofitted commercial buildings, to technology specific research projects, such as lighting, thermal storage, and office electronics. Recent studies include analysis of the costs and benefits of commissioning, and the development of information tools for commissioning, diagnostics, and performance tracking. Her research also included a sabbatical at the Chalmer's University of Technology in Gothenburg, Sweden. There she worked with the International Energy Agency's CADDET Technology Transfer Center. She has an M.S. in Mechanical Engineering from U.C. Berkeley, and a Licenciate from the Department of Building Services Engineering from Chalmers. 


\section{Background}

Despite significant advances in building technology and the promulgation of tighter building codes, buildings consume one-third of all energy in the US at a cost of $\$ 200$ billion per year, with $\$ 85$ billion per year for commercial buildings. A large amount, perhaps half of this energy use could be reduced using cost-effective technologies and improved operating strategies. Assuring total building performance, including health, productivity, cost-efficient operations, and energy efficiency, should be a national goal and a priority in an increasingly competitive world. Achieving this goal requires a re-examination of the process by which buildings are designed, built, and operated. A life-cycle perspective on how information is managed in the building sector provides useful new insights and opportunities for achieving improved building performance.

Computer-based information technology is one approach to address the loss of information that occurs as a building moves from design to commissioning and operations. This approach is the subject of a two-year Lab-Directed R\&D Building Performance Assurance project. Researchers at Lawrence Berkeley National Laboratory are examining problems associated with current building information systems and preliminary designs for Building Life-cycle Information Systems (BLISS). The Building Performance Assurance Project has three main subprojects. The first subproject deals with the conceptual design of BLISS. The second subproject is concerned with computer-based commissioning tools. The third subproject deals with computer-based performance tracking tools..

Commissioning test results can serve as the basis for the calibration of an as-built and as-operated cooling plant model for ongoing performance tracking, as further described in the next section. The last step in the commissioning process is to define long-term performance tracking methods Data collected during the commissioning phase can be used to update and calibrate the design simulations to reflect the as-built and as-operated conditions. Numerous metrics such as the coefficient of performance (COP) at standard conditions, annual integrated part load efficiency, and seasonal integrated part load efficiency have traditionally been used to measure the energy performance of HVAC systems such as chillers. These proxies describe the performance of a building HVAC system in a very limited fashion. More detailed information about performance must involve the dynamic behavior of the HVAC and building variables. Our objective in the third subproject is to use a dynamic model of the HVAC system to develop a methodology for carrying the performance-related information from the design phase to the commissioning phase, operations phase and even the retrofit phase. During the design phase, an HVAC model can be built using the design documents and manufacturer data on equipment performance. It is possible to emulate design options (such as different equipment sizes, efficiencies, etc.) and compare the projected energy performance of these different options, feeding information back results to the design process.

This paper presents an overview of current research to developed life-cycle information systems, focusing on commissioning tools. The paper begins with a brief discussion of the benefits of commissioning, followed by a discussion of previously developed computer-based methods to assist in the commissioning process. We then present a general overview of new research directions pursured at LBNL, and an introduction to a chiller commissioning software tool and case study results.

\section{Building Performance and Benefits of Commissioning}

How common are building performance problems? A recent study examined utility-funded . commissioning in 60 new commercial buildings with a detailed analysis of 16 buildings (Piette et al, 1996). We found that nearly every building had significant problems when performance is 
evaluated with functional performance tests. Specific information on the nature of the deficiencies was recorded in the utility's "War Story" list. The most common problems were related to controls. About one in five problems were so severe that they essentially defeated the savings from the utility funded energy-efficiency measures (EEMs). Typical costs for utility-funded commissioning of EEMs were $\$ 0.20 /$ sqft. The costs to commission the EEMs covered developing customized plans, reviewing results from functional tests, and following up to ensure that the most important deficiencies were corrected and documented in reports provided to the utility and building owner. Energy savings from correcting deficiencies were developed with DOE-2 simulations from the design models submitted to the utility as part of the Demand-Side Management program (Kaplan and Yoder, 1992). Commissioning was found to be cost effective on energy savings alone at most of the buildings. The simple payback time for commissioning as a stand-alone activity was derived by comparing the cost of commissioning to the energy costs savings from deficiency corrections. Under national average energy prices the median payback time for commissioning was about 3.5 years.

Non-energy benefits of deficiency corrections were tracked according to four primary categories of improvements: control, operations and maintenance, indoor-environmental quality, and equipment life. These benefits may be more important than energy saving benefits, but are difficult to quantify. Ensuring proper air flow in a building influences the health, safety, and productivity of the occupants. Energy costs in office buildings are around $\$ 2 /$ sqfit-year, while salaries of employees are about two orders of magnitude greater. The ultimate bottom line is the health and productivity of the occupants. Showing quantified occupant productivity gains in a well commissioned building compared to a building that is not commissioned is extremely difficult. However, we can show that the types of problems found during commissioning, left uncorrected, result in suboptimal building performance.

\section{Generating and Archiving Commissioning Plans and Test Results}

With the increasing capabilities of computer technology and reduced costs for monitoring equipment, the use of computer-based commissioning tools offer new possibilities for improving commissioning methods and reducing costs. To evaluate the potential advantages and disadvantages of computer-based commissioning tools it is important to understand how commissioning plans and test results are generated and archived. Commissioning plans are written for each project. Often the test plans will be based on tests developed at previously commissioned buildings, and are updated and customized for a specific building. The commissioning agent typically uses forms, such as that shown in Table 1 (included in the next section). Data sheets and forms are filled out, and might be submitted to the building owner on a weekly basis. This process is often cumbersome, inefficient, and unreliable. Previously developed computer-based applications for commissioning fall into the four categories described below. Both current and emerging applications are described.

EMCS-based commissioning. EMCS trend logs are used during most commissioning projects in buildings that are large enough to have an EMCS. The use of EMCS in commissioning have been discussed in several recent papers (see, for example, Heinemeier and Akbari, 1992, Tseng et al., 1994). The EMCS can used several ways. The EMCS itself must also be tested, sensor accuracy checked, and programming complete (which is often in flux over many months for a new building). A series of trend logs are usually delivered to the building owner to demonstrate that an EMCS is fully functional. An EMCS can be used as a field monitoring tool to $\log$ results from functional tests. There are often significant hurdles toward using the EMCS for commissioning, such as poor trend-logging capabilities. Advanced applications for commissioning of controls are emerging. Control simulators and emulators allow control systems to be modeled prior to installation. Such systems are common in industrial-control applications, 
and are beginning to be used in complex buildings. Control strategies can be tested prior to field installation. EMCS commissioning will be more efficient, and therefore less costly, with the use of simulators and emulators. Future EMCS will offer real-time simulation capabilities, allowing the operator to explore the energy and building performance implications of alternative control strategies.

Component characteristics tracking. One of the first tasks of a commissioning agent is to ensure that the installed equipment meet design specifications. This requires the agent to maintain a massive set of papers of construction documentation and detailed specifications. Recently, a Canadian software company joined forces with a commissioning agent to develop a computerbased commissioning tools. The software assists in tracking components after shop drawings are complete, and maintains records of equipment supplied and installed. Equipment specifications are recorded compliance with design specifications is captured through sub-system testing. Sets of common specifications and test templates are used for similar components. Maintaining the data set can be time consuming. However, once available in electronic form, the detailed description of building components can be used in Computerized Maintenance Management Systems (CMMS). LBNL 's computer-based Chiller Commissioning Tool, further discussed below, was developed from the component tracking application.

Energy balance simulation. A Short-Term Energy Monitoring (STEM) method has been developed by the National Renewable Energy Laboratory (Balcomb et al., 1994). STEM begins with two-days of intensive monitoring under controlled conditions. Results from the monitoring are evaluated to obtain building thermal loss, thermal mass, and solar gain data. Techniques have been developed to evaluate HVAC efficiency and perform HVAC diagnostics. STEM is primarily a research approach for building energy analysis.

Short-term HVAC data collection and analysis. The Electric Power Research Institute has supported the development of a Commercial Building Performance Evaluation System. (CBPES) to assist in commissioning (Waterbury, et al., 1994). CBPES combines monitoring hardware with data management and analysis software. The user enters information about the HVAC system and receives a monitoring plan. Metering equipment are deployed for two weeks, and the data are brought back for analysis. The system generated a standard set of diagnostic plots, which includes a set of baseline or comparison plots developed using DOE-2. CBPES has been field tested on several buildings and is an emerging tool for commissioning.

\section{Overview of Building Life-Cycle Information Systems}

It is useful to review the desired capabilities of Building Life-Cycle Information Systems to evaluate the gap between today's performance analysis tools and a fully integrated systems. The integrated system is concerned with providing the information infrastructure to support various activities in the specification, design, analysis, simulation, commissioning, operations, and diagnosis of building performance. The "information systems" under development will contain a repository for a distributed computing environment for connecting the various tools and building subsystems. The type of data to be recorded include:

- Programmatic Specifications - the number, size, and type of various rooms

- CAD Design - architectural, structural, mechanical, electrical, etc.

- Analysis and Simulation Model Inputs - assumptions for climate, schedules, HVAC specifications, etc.

- Analysis and Simulation Model Outputs - energy use, energy costs, etc. 
- As-Built and Shop Drawings

- Commissioning Data - commissioning plans, test results, deficiency records

- EMCS Data - point description, control policies, sensor calibration, trend logs

- Operations and Maintenance Data - energy use, cleaning and tuning, occupant complaint logs

- Retrofit History - Component tracking, equipment history and upgrades, renovation schedules

Table 1. Sample Pre-Start Water-Cooled Chiller Commissioning Inspection

\begin{tabular}{|c|c|c|c|c|}
\hline \multicolumn{5}{|l|}{ CHLLLER DATA } \\
\hline & AS DESIGNED & $\begin{array}{l}\text { AS } \\
\text { FOUND }\end{array}$ & $\begin{array}{l}\text { ACTION } \\
\text { REQUIRED }\end{array}$ & DONE \\
\hline \multicolumn{5}{|l|}{ MANUFACTURER } \\
\hline \multirow{2}{*}{\multicolumn{5}{|c|}{$\begin{array}{l}\text { MODEN NO. } \\
\text { SERIAL NO. }\end{array}$}} \\
\hline & & & & \\
\hline \multicolumn{5}{|l|}{ VOLTS/PHASE } \\
\hline \multicolumn{5}{|l|}{$\begin{array}{l}\text { MOTOR HP/RPM } \\
\text { REFRIGERANT TYPE }\end{array}$} \\
\hline \multicolumn{5}{|l|}{ REFRIGERANT CHARGE } \\
\hline \multirow{2}{*}{\multicolumn{5}{|c|}{$\begin{array}{l}\text { VIBRATION ISOL MANUF. } \\
\text { VIBRATION ISOLATTON TYPEIDEFLECTION }\end{array}$}} \\
\hline & & & & \\
\hline \multirow{3}{*}{\multicolumn{5}{|c|}{$\begin{array}{l}\text { REFRIGERANT DETECTOR DATA } \\
\text { MANUFACTURER } \\
\text { MODEL NO. } \\
\text { SERIAL NO. }\end{array}$}} \\
\hline & & & & \\
\hline & & & & \\
\hline \multicolumn{5}{|l|}{$\begin{array}{l}\text { VOLTS/PHASE } \\
\text { ALARM SETPOINT }\end{array}$} \\
\hline \multirow{2}{*}{\multicolumn{5}{|c|}{$\begin{array}{l}\text { ALARM SETPOINT } \\
\text { FAN SETPOINT }\end{array}$}} \\
\hline & & & & \\
\hline \multicolumn{5}{|l|}{ 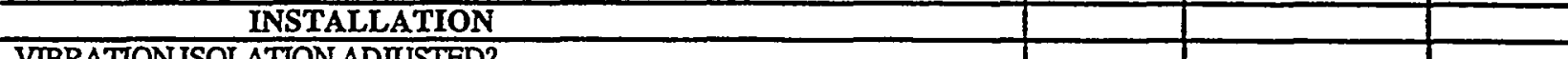 } \\
\hline \multicolumn{5}{|l|}{$\begin{array}{l}\text { VBBRATION ISOLATION ADJUSTED? } \\
\text { SHIPPING BLOCKS REMOVED? } \\
\text { SEISMIC RESTRANTS IN PLACE? }\end{array}$} \\
\hline \multirow{2}{*}{\multicolumn{5}{|c|}{$\begin{array}{l}\text { SEISMICRESTRAINTS IN PLACE? } \\
\text { PRESSURE GAUGES/TEST PLUGS INSTALLED? }\end{array}$}} \\
\hline & & & & \\
\hline \multicolumn{5}{|l|}{$\begin{array}{l}\text { TTERMOMETERS INSTALLED? } \\
\text { PRPNG COMPLETE? }\end{array}$} \\
\hline \multirow{2}{*}{\multicolumn{5}{|c|}{$\begin{array}{l}\text { PPING COMPLETE? } \\
\text { REFRIGERANT RELIEFPIPED TO OUTSDE? }\end{array}$}} \\
\hline & \multicolumn{4}{|c|}{ ELECTRICAL CONNECTIONS COMPLETE? } \\
\hline \multicolumn{5}{|l|}{ MANUFACTURER'S TEST \& START-UP COMPLETE? } \\
\hline MANUFACTURER'S START-UP SHEETS ATTACHED & & & & \\
\hline NOTES & & & & \\
\hline
\end{tabular}

We are examining the existing, incomplete infrastructure of such data and tools, adding to, integrating, and restructuring these elements to meet performance objectives such as optimized energy efficiency and environmental quality throughout the building life cycle. Although no current set of tools or database schema exists today to manage such diverse information, current design tools offer significant new capabilities for tracking data from compiled for and generated from the design process such as simulations results or comparison building data.

Computer-based information technology is one approach to address the loss of information that occurs as a building moves from design to commissioning and operations. Since one of the critical 
functions of commissioning is to test building systems to ensure they conform with "design intent," we have examined information available on the "design intent." Design simulations contain a description of key assumptions used to evaluate energy performance and can be a useful starting point for developing functional tests that are intended to examine if the building system meet key energy efficiency and related design criteria. Ideally the generation of a commissioning plan itself would be linked to the design simulations. Data collected during the commissioning phase can be used to update and calibrate the design simulations to reflect the as-built and asoperated conditions. As mentioned, the calibrated model can then serve as the basis for ongoing performance evaluation and tracking.

While interopretability is not a new idea for building software, the recent spawning of an industry based effort to address the development of interoperable software, combined with continuing advances in computer technology, suggest that such tools are becoming a reality, supporting increasing interoperability. The Industry Alliance for Interoperability (IAI) was formed to represent major segments of the building industry, such as $\mathrm{CAD}$, controls, construction management, HVAC, and facilities maintenance management companies. The IAI is collaborating to establish a de facto standard for interoperable software. More than 11 companies joined the Alliance to define and develop open, object oriented architecture that allows information sharing among various phases of the building life cycle. Near term successes in development of applications that use the Industry Foundation Classes will be critical to building credibility and long-term success.

To develop a prototype design of an integrated information system we chose a particular building subsystem to work with: chillers and related chilled water systems. Chillers are the largest single energy-using component in buildings with central plants, consuming about $10 \%$ of the annual electricity use at our case study building on the U.C. Berkeley campus. The following section describes our efforts to develop stand-alone commissioning and case study activities.

\section{Computer-Based Chiller Commissioning Tool and Field Tests}

We are developing a prototype chiller commissioning tool to assist in the construction, execution, and archiving of commissioning plans. The general steps in applying the tool are outline in Figure A. The first step in applying the software is to describe the characteristics of the chiller components, such as chiller size, type, warranty dates, flow rates, pressure drops, and operating temperatures. The software contains a general description of chiller commissioning activities and a module to record specific test plan methods customized for a particular building (Step 2). Standard forms like those used in most commissioning programs can be tailored and generated for the specific cooling plant systems. The database schema was developed to allow for laptop computers to be used to track changes to test plans and collect data during plan execution (Step 3). Test plans and test results are then available to future building operators who might want more details than current paper versions of commissioning reports provide. Test results are recorded and outstanding issues and deficiencies are tracked to determine if the chiller is fully functional (Step 4). The ability to track deficiencies is one of the most practical elements of the software in use today. The contractor or equipment supplier responsible for the components or systems can be recorded and identified to follow up with deficiencies, or as a reference for operators after commissioning is complete. 


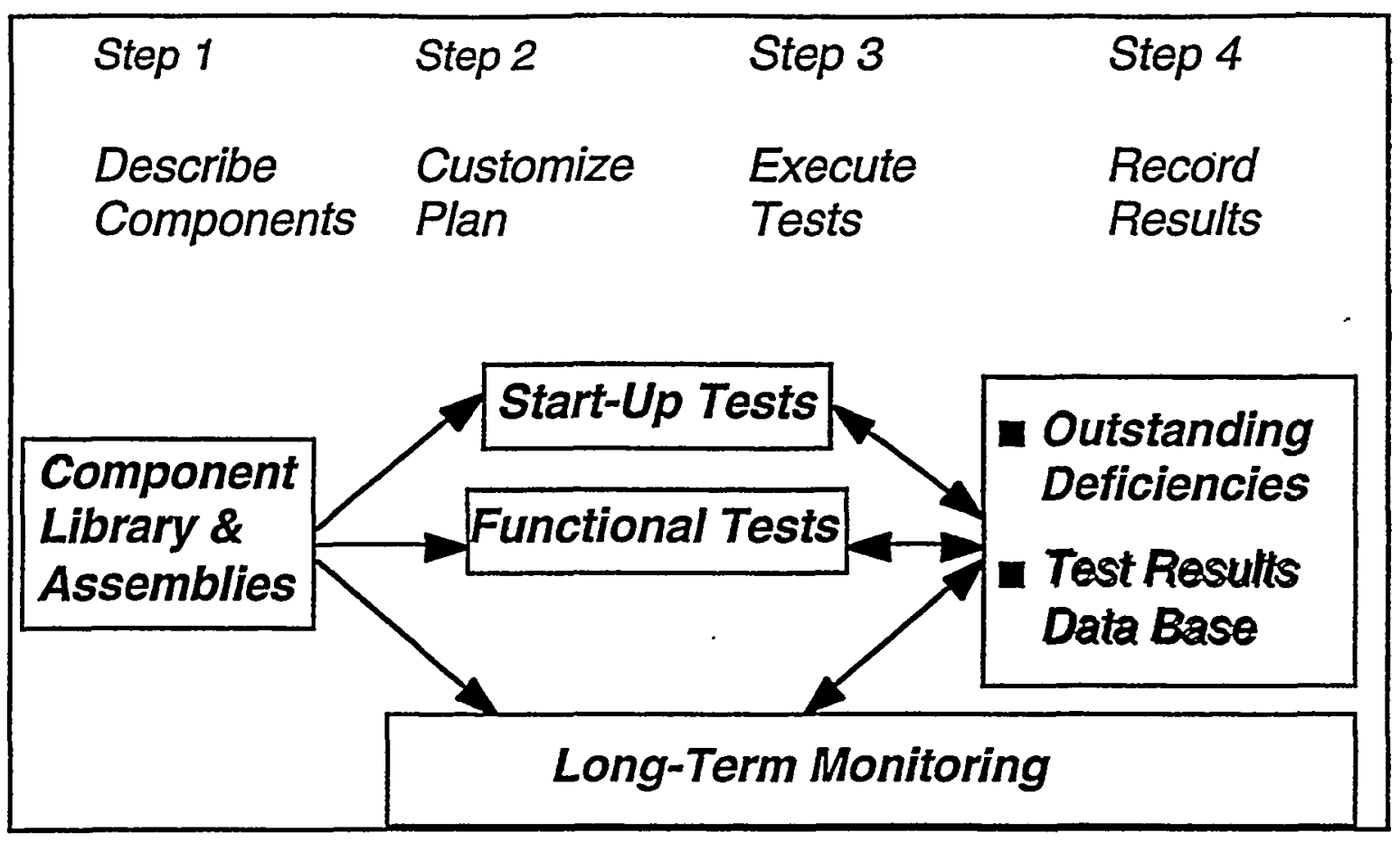

Figure A. Steps in using Computer-Based Chiller Commissioning Tool.

The commissioning and performance tracking activities at our case study site consisted of the following major steps:

- Compile HVAC specifications, control sequences, and as-built documents

- Conduct short term measurements to characterize flows, temperatures, and pressures

- Install long-term, permanent metering equipment for as-operated model calibration and diagnostics using the EMCS as the data acquisition system

- Conduct false load test of chillers to evaluate $\mathrm{kW} /$ ton at partial and full loads

- Develop calibrated model of the chillers

- Identify and implement improved control sequences

- Conduct additional power measurements on cooling towers for use in estimating energy savings from set point optimization

We have found several significant design errors related to issues such as oversizing, improper valve selection. Commissioning of the cooling plant has resulted in several thousands of dollars of savings from the interventions. These findings will be discussed in a forthcoming paper documenting the results of our investigations. This building is serving as a living laboratory for an integrated information system as we combine design, commissioning, and performance tracking data to evaluate a variety of important building performance parameters. One product of this work will be a better understanding of how to to develop performance specifications. since we're looking closely at how various component perform in comparison to manufacturer's specifications.

\section{Summary and Acknowledgements}

This paper discussed information management applications for critical phases of the building life cycle, focusing on commissioning. Many of today's building performance problems are related to the lack of formal, rigorous commissioning. We are developing prototype chiller commissioning software to help track activities to evaluate whether a building performs as intended. We also described a computer-model-based performance tracking that begins where the commissioning 
software ends. A case study of commissioning and performance tracking showed that design, commissioning, and operating deficiencies result in thousands of dollars of cost overruns. During the second year of the project we are continuing to refine the tools developed during the first year and evaluating techniques to expand the tools to be interoperable with other computer-based building life-cycle information tools.

This project has involved numerous researchers at LBNL plus others outside of LBNL. In addition to the author, the principle investigators include Steve Selkowitz, Max Sherman and Frank Olken. The results presented here represent research in progress. We are actively evaluating partnership opportunities to further develop the concepts outlined above. Ongoing collaboration and careful coordination among researchers, industry software developers, users, and practitioners is needed to ensure that the system's under development are practical yet robust, and support the applications needed to improve building performance. The commissioning software is being developed in partnership with Wayne Dunn, Sunbelt Engineering, and Weibo Troost and Tim Edlund of Softworks, Inc. Chiller commissioning procedures were developed by Steve Taylor, Taylor Engineering. Special thanks also to James Patterson, Sara Shirazi, Carlo Sequin, of U.C. Berkeley. This work was partially supported by the Assistant Secretary for Energy-Efficiency and Renewable Energy, Office of Building Technologies, Building Systems Division of the U.S. Department of Energy under Contract No. DE-AC03-76SF00098.

\section{References}

Balcomb, J.D., Burch, J.D., and Westby, R.D., "Whole Building Commissioning Based on Model Calibration: Refitting the Crown Jewel," Proceedings of the 1994 Summer Study on Energy Efficiency in Buildings, American Council for an Energy-Efficient Economy, Washington D.C., August 1994.

Heinemeier, K.E., and Akbari, H., "Proposed Guidelines for Using Energy Management and Control Systems for Performance Monitoring." Proceedings from the ACEEE 1992 Summer Study on Energy Efficiency in Buildings, American Council for an Energy-Efficient Economy, Washington D.C., August 1992.

M. A. Piette, and B. Nordman, "Costs and Benefits of Utility Funded Commissioning of EnergyEfficiency Measures in 16 Buildings", ASHRAE Transactions, Atlanta, GA, Vol. 102, Pt 1. Feb. 1996, LBNL-37823.

Tseng, P.C., Stanton-Hoyle, D.R., and Withers, W., "Use of a Supplemented EMCS in Commissioning," Proceedings of the ACEEE 1994 Summer Study on Energy Efficiency in Buildings, Washington D.C., August 1994.

Waterbury, S.S., Frey, D.J., and Johnson, K.F., "Commercial Building Performance Evaluation System for HVAC Diagnostics and Commissioning," Proceedings of the ACEEE 1994 Summer Study on Energy Efficiency in Buildings, American Council for an Energy-Efficient Economy, Washington D.C., August 1994.

Yoder R. and Kaplan M. "Building Commissioning for Demand-Side Resource Acquisition Programs," Proceedings of the ACEEE 1992 Summer Study on Energy Efficiency in Buildings, American Council for an Energy-Efficient Economy, Washington D.C., August 1992. 
. 
